\title{
Terapia fonoaudiológica em grupo voltada à linguagem escrita: uma perspectiva dialógica
}

\section{Speech therapy group focused on written language: a dialogical perspective}

Rita Signor*

Universidade Federal de Santa Catarina

Florianópolis - Santa Catarina / Brasil

RESUMO: Apresento neste artigo um recorte de uma pesquisa na qual elaborei uma proposta terapêutica, ancorada na teoria de gêneros do discurso de Bakhtin (2003), com o objetivo de analisar a contribuição da referida teoria para a clínica fonoaudiológica. Para tanto, desenvolvi um estudo de caso com um grupo de cinco sujeitos com queixas de dificuldades de leitura e escrita. Os gêneros selecionados para o trabalho em terapia foram: romance, peça de teatro, sinopse e cartaz de divulgação. Por questóes de espaço, apresento aqui parte da interação com os sujeitos do grupo em processo de escrita em apenas um dos gêneros abordados: o gênero peça de teatro. Os resultados sugerem que as práticas ancoradas em uma perspectiva enunciativo-discursiva foram efetivas, pois, por meio de contextos significativos de uso da língua, os sujeitos se aproximaram da escrita e da leitura e com isso desenvolveram competências necessárias à interação nessas práticas.

PALAVRAS-CHAVE: dificuldades de leitura e escrita; gêneros do discurso; terapia fonoaudiológica

ABSTRACT: In this paper I present a part of a research in which I propose a therapy based on Bakthin's theory about speech genres. My objective was to analyze the contribution of this theory to clinical speech therapy field. In order to perform my proposal, I have developed a case study in a group formed by five subjects who had complaints about their reading and writing skills. I have selected the following genres in our work: novel, play, synopsis and publicity poster. Because of the size of this paper, here I will present just the interlocution with the subjects of the group during the process of writing the play. The results suggest that practices based on a discursive perspective were effective because the group - immersed in meaningful contexts of language use - developed linguistic and discursive competences necessary in reading and writing.

KEYWORDS: writing and reading difficulties; speech genres; speech therapy

* ritasignor@gmail.com. Doutoranda em Linguística pela Universidade Federal de Santa Catarina. Professora convidada do Programa de Fonoaudiologia da UFSC. Bolsista do CNPq. 


\section{Introdução}

É grande o número de encaminhamentos à clínica fonoaudiológica de sujeitos que supostamente não correspondem às expectativas da escola. Os chamados "distúrbios" de linguagem escrita têm motivado a criação de centros de diagnóstico em vários países. O que prevalece nesses centros é a noção de que esses distúrbios são decorrentes de fatores orgânicos que acometem o indivíduo, prejudicando o desenvolvimento da linguagem escrita (MASSI, 2007). Para Massi, há uma imprecisão nas teorias que sustentam o caráter constitutivo dos distúrbios de leitura e escrita, já que nessas teorias o percurso de apropriação da linguagem pelos sujeitos carece de explicações de vezo sociodiscursivo.

Ainda, os manuais que pretendem orientar o fonoaudiólogo nos procedimentos de avaliação em linguagem escrita estão voltados para testes padronizados, estendidos ao acaso a todos os sujeitos. Tais testes, pautados em estudos da área médica (neurologia), tomam como escopo alterações de leitura e escrita em indivíduos que sofreram lesão cerebral (afasia). Massi (2007) revela que amparar produções escritas de sujeitos em pleno processo de apropriação dessa modalidade da linguagem com as produções de sujeitos afásicos é um equívoco que necessita ser reinterpretado. Mesmo no caso das afasias, existem estudos que contestam os testes padronizados. Coudry (1988), por exemplo, diz que os testes buscam a localização topográfica de lesões cerebrais mediante tarefas que se distanciam da linguagem como atividade discursiva e interativa. A autora assinala que não é possível, por meio de testes-padrão, encontrar um caminho de compreensão em relação ao fenômeno descrito (sintomas linguísticos presentes nos sujeitos com afasia).

O mais problemático, sob meu modo de ver, é que após detectado o "distúrbio" de linguagem parte-se para a "terapia". Há um domínio na fonoaudiologia de procedimentos terapêuticos que distanciam os sujeitos de práticas sociais de leitura e escrita. Inclusive, muitos dos testes de "consciência

\footnotetext{
${ }^{1} \mathrm{O}$ termo distúrbio está entre aspas porque acredito que as situações de testagem, ao desconsiderarem justamente o que deveriam considerar - o sujeito - sua historicidade, e a linguagem como fenômeno discursivo, terminam por gerar diagnósticos de supostas dificuldades de aprendizagem em sujeitos que estão em fase de apropriação da linguagem escrita. $\mathrm{O}$ aluno que já vinha sendo estigmatizado na escola, ao receber o diagnóstico clínico, acaba, muitas vezes, incorporando uma autoimagem negativa em relação à sua condição de sujeito aprendiz.
} 
fonológica" e de "processamento auditivo", os mais utilizados na clínica, são usados para orientar as práticas terapêuticas.

Descrevo abaixo, a título de ilustração, algumas das atividades de processamento auditivo ${ }^{2}$ que são realizadas em clínica no que se entende como terapia de linguagem escrita. Tais procedimentos foram extraídos de Margal (2004):

- Conscientize a criança de suas dificuldades em relação ao processamento auditivo central, quais aspectos serão trabalhados e de que forma serão enfocados;

- Dê mais ênfase aos sons ambientais, dentre os sons não verbais, pois são mais significativos e propiciam maior exploração da linguagem do que os sons instrumentais;

- Dentre os sons verbais, parta sempre do que é mais saliente para o menos saliente, por exemplo: frases, palavras, morfemas, rimas, sílaba, fonema;

- Ofereça pistas visuais para facilitar a compreensão da criança;

- Assegure a atenção da criança durante toda a sessão através de material motivador e reforço positivo: abraços, sorrisos, bom humor, uso de expressão corporal e entonação corretas para cada atividade;

- Treine na criança a habilidade de presença e ausência dos sons. O treinamento prévio com estímulos não verbais pode ser um pré-requisito para a introdução dos estímulos verbais;

- Inclua sons ambientais como bater os pés no chão, bater a porta, bater na porta, arrastar cadeiras, estalar os dedos, amassar papel, bater palmas, tossir, barulho de moedas, chaves, riso, choro, bater no vidro etc.

No contexto dessas atividades, cabe indagar: é possível que se trabalhe a linguagem nos seus usos sociais por meio dos procedimentos acima sugeridos? Que concepção de linguagem norteia a corrente que defende o

\footnotetext{
${ }^{2}$ Importante comentar que tais testes têm sido realizados de forma indiscriminada na clínica fonoaudiológica, já que dados de pesquisas, como os de Santos e Navas (2004), informam que $80 \%$ das crianças consideradas portadoras de distúrbios de leitura e escrita apresentam também desordens do processamento auditivo central. Assim, tais pesquisadores, ao delegar a natureza dos problemas de escrita aos distúrbios do sistema de processamento da audição, preconizam que o estímulo das habilidades auditivas, por exemplo, a de localização de estímulos verbais e não verbais, são condiçóes necessárias e suficientes para o desenvolvimento da linguagem escrita nos pacientes.
} 
diagnóstico e a terapia de escrita baseada no processamento auditivo? Existe uma teoria de linguagem que subjaz a toda essa bateria de procedimentos? Essa teoria dá conta da realidade concreta do fenômeno da linguagem?

Sendo assim, torna-se relevante na área da fonoaudiologia a realização de estudos que tomem a linguagem em sua dimensão constitutiva, histórica e social (BERBERIAN; MASSI, 2005). Por esta concepção, o sujeito e os processos de linguagem são tomados de outra forma, tanto na condução da avaliação quanto da terapia em linguagem. A apropriação da escrita é vista como decorrente de interaçôes sociais mediadas por práticas discursivas. Os "erros" ortográficos, por esta vertente, nada mais são do que indícios (ABAURRE, 2006) de reflexões do aprendiz sobre o objeto do conhecimento; indícios singulares, pois refletem a história de cada sujeito e, nessa história, revelam a maior ou menor inserção em práticas mediadas pela leitura e escrita.

Neste artigo apresento um recorte de minha dissertação de mestrado ${ }^{3}$ (em Linguística) na qual objetivei elaborar uma proposta terapêutica baseada na teoria de gêneros do discurso de Bakhtin. Justifico minha opção em favor dos gêneros do discurso como mediadores do trabalho voltado para a área da leitura e escrita, pois preconizo que através das relações de sentido que a teoria pressupõe, seja possível diluir manifestaçôes negativas frente à modalidade escrita da linguagem. Penso que uma atuação mediada pela noção de gêneros tende a inserir o sujeito em práticas sociais de leitura e escrita, repercutindo, por meio dessa inserção, no desenvolvimento de competências linguísticas e discursivas, para uma participação mais ativa/efetiva em uma sociedade letrada.

Ressalto que a adoção de uma perspectiva enunciativo-discursiva neste trabalho é de natureza clínica, inserida no campo de ação da fonoaudiologia. Sem esquecer a dimensão pedagógica implicada na perspectiva teórica assumida, é importante lembrar que a situação de terapia projeta um outro lugar de mediação e de aprendizagem (diferente do dos contextos formais). Em situação terapêutica, o profissional tem a função de ressignificar relaçôes de sofrimento dos sujeitos com a linguagem e com a própria condição de capacidade linguística. Para isso, é necessário conhecer as interaçôes às quais esses sujeitos estão submetidos, para, a partir de um paradigma enunciativo, agir na

\footnotetext{
${ }^{3}$ Esta pesquisa passou pelo Comitê de Ética em pesquisa da Universidade Federal de Santa Catarina, sob número 132/09. Foram assinados os Termos de Consentimento Livre e Esclarecido. A pesquisa foi orientada pela professora Dra. Rosângela Hammes Rodrigues.
} 
ressignificação da queixa. Assim, a construção de novos sentidos nas vivências mediadas pela língua escrita conduz ao redimensionamento de uma autoestima muitas vezes comprometida pelo estigma da "dificuldade" de leitura e escrita; é nesse ponto que o trabalho empreendido ultrapassa o campo "pedagógico" e se torna terapêutico (fonoaudiológico).

\section{Método}

Para dar conta do objetivo delineado, elaborei, desenvolvi e avaliei uma proposta de pesquisa e terapêutica, que configurei como um estudo de caso de um atendimento fonoaudiológico em grupo. $\mathrm{O}$ grupo foi composto por cinco sujeitos, entre onze e treze anos, estudantes do $4^{\circ}$ e $5^{\circ}$ ano do ensino fundamental, que foram encaminhados por suas escolas por apresentarem, segundo parecer dos professores, dificuldades relacionadas à linguagem escrita (compreensão e produção escrita).

$\mathrm{Na}$ voz dos professores as "dificuldades" de linguagem escrita apresentadas pelos alunos se deviam, em grande medida, às questôes comportamentais e à falta de interesse em participar das atividades desenvolvidas em sala de aula; algo que pode ser observado em alguns trechos contidos nos relatórios de encaminhamento:

"Há muitas queixas de dores: de cabeça, de barriga e na bexiga"; "Parece incomodada muitas vezes durante as atividades pedindo para sair e dar uma voltinha"; "Mostra-se apática, não parece alegre"; "Sua figura demonstra diferenças entre os alunos mais saudáveis, alegres, comunicativos, criativos"; "É disperso, não consegue manter-se sentado por muito tempo"; "Durante as explicaçōes para a realização das atividades mostra-se distraído e não faz perguntas"; "A maioria dos colegas prefere não realizar atividades em dupla com ele"; "Muitas vezes seu olhar está distante, sendo chamado muitas vezes para olhar para o quadro ou para a professora”.

Tais questões não serão aprofundadas, pois considero que o discurso escolar é em grande medida previsível e redundante: impõe a palavra de uma instituição que exclui ao invés de acolher, e que vê no encaminhamento à clínica uma fonte de descomprometimento em relação aos "problemas"/ processos de linguagem escrita apresentados pelos alunos.

Os sujeitos realizaram avaliação fonoaudiológica e nessa constatei que não possuíam distúrbios ou dificuldades de leitura e escrita, uma vez que suas produções textuais permitiam a construção de sentidos por parte do leitor. Além disso, as instabilidades em torno dos aspectos formais da língua foram 
tomadas como inerentes ao processo de apropriação da linguagem. Desse modo, a aceitação para terapia ocorreu, tão-somente, em virtude da queixa da escola que, refletindo no discurso dos alunos/pacientes, acabou gerando uma rejeição por parte deles em relação às práticas de leitura e escrita, traduzidas da seguinte forma: "detesto ler e escrever"; "escrevo tudo errado"; "sento lá atrás [na sala de aula] e não faço nada!"; "não sei”; "não consigo" etc.

$\mathrm{O}$ atendimento clínico foi embasado na perspectiva enunciativodiscursiva de linguagem e a concepção bakhtiniana de gêneros do discurso fundamentou teoricamente a atuação fonoaudiológica. Assim, após conversas iniciais com os sujeitos, selecionei um grupo de gêneros do discurso para nortear a ação terapêutica: romance, peça de teatro, cartaz de divulgação e sinopse. Dentre esses, a peça de teatro foi priorizada, sendo os demais decorrentes e necessários ao enfoque centrado em uma proposta de elaboração, publicação e encenação de uma peça. Para a escrita da peça de teatro, partiu-se da reenunciação de um romance ${ }^{4}$ lido em terapia. E para a publicação da peça em site e sua encenação, os sujeitos produziram os gêneros sinopse e cartaz de divulgação. Nesse contexto, os participantes da pesquisa se inseriram em uma série de práticas sociais de leitura e escrita visando à concretização da ação fonoaudiológica voltada para a apropriação, pelos sujeitos, das práticas de leitura e produção de textos mediados por esses gêneros.

Os dados foram gerados no período de novembro de 2008 a janeiro de 2010. As sessões, que ocorriam uma vez por semana e tinham em média três horas de duração, foram documentadas com auxílio de um gravador de áudio e de um diário de pesquisa. Outros instrumentos de pesquisa foram: questionários respondidos por escrito pelos pais, entrevistas com os pais, relatórios dos professores e prontuários médicos. As transcrições das falas seguiram a convenção da escrita. $\mathrm{O}$ atendimento foi realizado em uma sala do ambulatório de leitura e escrita de um hospital infantil. As sessões foram realizadas em grupo, com alguns atendimentos individuais.

Vale considerar que, para este artigo, por questões de espaço, apresento parte da interlocução com os sujeitos do grupo em processo de escrita em apenas um dos gêneros abordados em terapia: o gênero peça de teatro. Os

\footnotetext{
${ }^{4}$ Neste romance (Goosebumps - ele saiu debaixo da pia) dois irmãos, Kat e Daniel, encontram na casa para a qual acabaram de se mudar um objeto/esponja - o grool - que traz azar a quem o possuir. Durante a trama, os irmãos tentam se livrar do grool, mas ele parece imortal.
} 
sujeitos são apresentados por suas iniciais: J, D, L, ED e M. A terapeuta/ pesquisadora recebe o $\mathrm{T}$.

Para dar tratamento analítico-qualitativo aos dados gerados nos episódios dialógicos, resultantes de um estudo longitudinal, tomei a teoria enunciativodiscursiva explicitada por Bakhtin (Análise Dialógica do Discurso - ADD). Uma abordagem epistemológica sócio-histórica que se oriente pelas concepções bakhtinianas tem, como categoria central, o dialogismo, uma vez que busca atingir os sentidos estabelecidos e promovidos nas situaçôes interacionais.

A seguir um resumo das sessões terapêuticas destinadas ao trabalho voltado para o gênero peça de teatro.

\section{O trabalho com o gênero peça de teatro}

- $1^{a}$ sessão: apresentação dos objetivos do trabalho terapêutico e de pesquisa; conversa inicial a respeito do gênero peça de teatro (estudo dos aspectos históricos e da esfera da arte dramática, segundo Berthold (2008) e Peixoto (1981)).

- $2^{a}$ a $4^{a}$ sessões: seleção e leitura do romance (objeto de adaptação): Goosebumps - ele saiu debaixo da pia, de R. L Stine.

- $5^{\mathrm{a}}$ a $11^{\mathrm{a}}$ sessões: 1 - leituras e análises de peças de teatro em diferentes modalidades (drama, comédia e tragédia). 2 - estudo das propriedades textuais do gênero peça de teatro, como marcação das microrrubricas e macrorrubricas, ${ }^{5}$ segundo Cobra (2009). 3 - leituras de entrevistas com dramaturgos e elaboração de entrevista para um dramaturgo. 4 - leituras de trechos das obras Clarissa, de Erico Veríssimo, e Crepúsculo, de Stephanie Meyer, para comparação entre gêneros (romance e peça de teatro). Tal atitude objetivou clarificar alguns aspectos relacionados à composição textual do gênero peça de teatro, como, por exemplo, a questão dos tempos verbais (tempo presente - nas indicações de cena - na peça,

\footnotetext{
${ }^{5}$ As rubricas são divididas em macrorrubricas e microrrubricas. As primeiras indicam o que ocorre em cena, se é dia ou noite, se a cena é interna ou externa, e traz indicações para a composição do cenário. A macrorrubrica também é chamada de vista e fica no centro da página, na parte superior de cada cena, escrita em itálico ou em letra maiúscula. A microrrrubrica é mais específica, encontra-se no corpo do texto e afeta a ação cênica; são divididas em objetivas e subjetivas. As microrrubricas objetivas se referem à movimentação dos atores e as subjetivas indicam estados emocionais dos personagens, bem como o tom das falas (COBRA, 2009).
} 
e tempo pretérito no romance). Para isso, estudamos a função social de cada gênero (interação imediata com o público na peça de teatro e interação distante no romance).

- 12a a $18^{a}$ sessóes: escrita da peça ${ }^{6}$ (parte 1): os vinte e nove capítulos do romance foram divididos entre os sujeitos para que eles realizassem a reenunciação do gênero romance para o gênero peça de teatro. Essa primeira parte de escrita foi centrada nos seguintes aspectos: indicação dos personagens no canto esquerdo da página e marcação das microrrubricas.

- 19a a $21^{\text {a }}$ sessões: escrita da peça (parte 2): após união dos capítulos ${ }^{7}$ reenunciados (do romance) para a peça de teatro, o grupo procedeu à divisão da peça em cenas (pautada na entrada e saída de personagens) do texto produzido. Os sujeitos também realizaram a marcação das macrorrubricas.

- $22^{\mathrm{a}}$ a $25^{\mathrm{a}}$ sessões: ${ }^{8}$ após o processo de escrita foi realizada a revisão da peça inteira produzida pelo grupo. Cada integrante revisou inclusive a parte escrita pelos colegas.

Na sequência, apresento parte da interlocução em grupo referente à $13^{\mathrm{a}}$ sessão de terapia.

\section{Resultados}

\section{A produção da peça de teatro em grupo}

O processo de produção da peça de teatro em grupo é o ponto norteador desta seção. Para tanto, começo apresentando um episódio em que J entra em discussão com seus colegas, pois fica em dúvida com relação a uma indicação de personagens. Nessa indicação, dois personagens falariam ao mesmo tempo, seguindo a adaptação do diálogo presente no livro, conforme se pode observar no trecho: - Sumiu? - Daniel e eu gritamos ao mesmo tempo. Como essa foi uma

\footnotetext{
${ }^{6} \mathrm{O}$ grupo, antes de iniciar a escrita da peça, assistiu a uma peça de teatro, no teatro da UBRO, em Florianópolis. Isso aconteceu no final de semana.

7 Digitei, preservando a escritura dos sujeitos, todas as produções individuais, unindo-as em uma peça completa. Entreguei uma cópia para cada participante do grupo para o seguimento do procedimento terapêutico.

${ }^{8}$ As demais sessões, 46 ao todo, foram destinadas aos ensaios, encenação e também ao trabalho com os gêneros sinopse e cartaz de divulgação.
} 
situação inusitada durante o trabalho com a produção escrita da peça de teatro, $\mathrm{J}$ não sabia de que forma proceder e então refletiu com seus colegas de grupo:

(01) [19/03/2009]: Referente à reenunciação do capítulo 10 do romance.

$\mathrm{J}$ : T, como eu faço aqui? São dois falando junto.

T: Quem tá falando junto?

J: A Kat e o Daniel.

T: Tão falando o quê?

J: Sumiu? É que o Valente [cachorro da família] sumiu.

T: Como é que você acha que é?

J: Não sei...

[...]

T: (Olha para o grupo) Alguém sabe?

(Silêncio)

D: Bota Kat, Daniel.

M: Póe Kat dizendo sumiu (faz com voz fina) e Daniel falando sumiu (fala com voz grossa), não tem que pôr igual do livro, põe cada um falando...

A interação acima pode ser interpretada à luz das posiçōes de Geraldi (1997), que diz que toda relação intersubjetiva pressupõe um $e u$ e um $t u$, sujeitos do discurso, situados em uma determinada formação social. "Daí compreender a linguagem como trabalho constitutivo dos sistemas de referências ${ }^{9}$ e dos sujeitos cujas consciências se formam precisamente pelo conjunto de categorias que vão incorporando, enquanto signos, nos processos interlocutivos de que participam" (GERALDI, 1997, p. 14). É possível observar no enunciado dos sujeitos uma ação de linguagem conjunta. Dada a dúvida de J, M e $\mathrm{D}$ apresentaram estratégias possíveis para que ela resolvesse seu impasse. Foi possível perceber que na situação de interação em grupo de terapia foram se construindo possíveis estratégias de escrita para as dúvidas apontadas por J na interlocução. Foram apresentadas não uma, mas duas possíveis soluções para o problema e ela pôde ainda refletir sobre qual a mais adequada a seu projeto discursivo.

Outra observação referente ao episódio acima diz respeito ao enunciado de M: não tem que pôr igual do livro, põe cada um falando. Seu discurso demonstrou o quanto ele se apropriou do processo de produção de uma peça teatral e, nesse caso específico, por meio da reenunciação de um romance, pois

\footnotetext{
${ }^{9}$ Sistemas de referências são, conforme Geraldi (1997), uma organização não formal de modos de ver e compreender o mundo, explicitada em uma determinada cultura histórica.
} 
trouxe para a interação discussões realizadas em outras sessões, em que eu havia dito que na realidade eles realizariam uma adaptação, não uma transcrição literal do romance. Podemos, na análise dessa passagem, trazer à tona a discussão de Bakhtin acerca do processo de apropriação do discurso do outro. Segundo o autor, "Para cada indivíduo, todas as palavras se dividem nas suas próprias palavras e nas do outro, mas as fronteiras entre elas podem confundir-se, e nessas fronteiras desenvolve-se uma luta dialógica" (BAKHTIN, 2003, p. 379). O conhecimento expresso no enunciado de $\mathrm{M}$ não tem que pôr igual do livro, pode-se inferir, pelo acompanhamento do grupo, que não fazia parte do conhecimento dele antes do processo terapêutico e, portanto, não the pertencia. A partir do momento que toma significação e entra em seu discurso, a palavra do outro, e o conhecimento que ela traz, passa a lhe pertencer e ser também sua (minha/alheia), quebrando-se as fronteiras entre a palavra do outro e a palavra dele. Ao usar o conhecimento construído sobre o processo de adaptação das falas dos personagens do romance para a peça de teatro, $M$ se constitui na relação dialógica, pois compartilha o saber e, nesse processo, também se completa, pois não apenas recebe o discurso do outro, mas também o partilha com o outro (participantes do grupo). Como resultado do processo dialógico, apresento a adaptação realizada por $\mathrm{J}$ do trecho do romance que instaurou a discussão:

MÃE - Valente sumiu!

KAT, DANIEL - Sumiu! (gritam ao mesmo tempo)

MÂE - Ele fujiu! - Não consigo achá-lo em nenhum lugar!

[19/03/2009]: Parte do roteiro ${ }^{10}$ escrito por J.

- Valente sumiu - minha mãe anunciou mordendo o lábio inferior.

- Sumiu? - Daniel e eu gritamos ao mesmo tempo.

- Ele fugiu - minha mãe explicou. - Não consigo achá-lo em nenhum lugar. Ele deve ter escapado quando eu guardei algumas coisas na garagem. (trecho do romance)

Ainda a respeito da produção de J, outra questão foi colocada por mim na sessão, como interlocutora de J, que estava relacionada ao fato já comentado em sessões anteriores e que se referia ao modo de textualização dos pensamentos dos personagens na peça. J ainda não estava sabendo como lidar com essa questão em sua produção escrita, então pedi a ajuda do grupo novamente:

\footnotetext{
${ }^{10}$ Nomeamos o gênero em questão por peça de teatro ou roteiro de teatro. Ressalto que o termo roteiro está diretamente relacionado ao texto escrito, ao passo que peça de teatro recobre também a encenação.
} 
(02) $[19 / 03 / 09]$

T: Aqui ${ }^{11}, \mathrm{~J}$, não é pensei...

J: Pensa...

T: Mas como é que o povo que vai tá assistindo a peça, vai ver o pensamento da Kat? Gente (diz pra todos), como é que a gente faz pro pensamento de um personagem aparecer em cena?

$\mathrm{J}$ : Tira.

D: Não. Tem que pôr a Kat falando ou fazendo alguma coisa.

M: É importante? Se é importante não dá pra tirar...

T: Qual é o pensamento, J?

J: (lê) Pobre Valente, pensei, certo com medo e assustado...

D: Isso não dá ação.

T: Põe ela falando isso...

L: Ih... vai ter que falar sozinha...

T: Tem que pôr como se ela tivesse falando sozinha mesmo... Tipo falando baixinho... meio que sussurrando... pra dá a impressão que ela tá pensando... (discute mais a questão).

A situação acima revela o quanto o atendimento em grupo pode ser efetivo, pois propicia a construção conjunta do conhecimento. No grupo é criado um espaço de ensino-mediação-aprendizagem (não necessariamente nessa ordem). Nesse espaço, os papéis, inicialmente, podem ser assim distribuídos: o terapeuta é o mediador, é aquele que realiza as perguntas geradoras de desenvolvimento, é aquele que leva os sujeitos a refletirem sobre a linguagem e, ao mesmo tempo, oportuniza situaçóes para que as experiências entre os integrantes do grupo sejam trocadas. Mas esses papéis não são fixos, pois as funções de ensinar e aprender são intercambiadas por todos dentro do grupo, ou seja, todos os componentes, inclusive a terapeuta, ora ensinam, ora aprendem uns com os outros.

Essa responsabilidade/comprometimento com o outro, com o aprender do outro, pode ser compreendida como responsabilidade e comprometimento consigo mesmo também. Essa parceria com o grupo advém, dentre outros aspectos, de vivências/experiências anteriores; o outro, o parceiro de terapia, é aquele que igualmente já passou por situações de exclusão e estigma; é como se com a convivência fosse se formando um estado de acolhimento recíproco (MACHADO, 2007). É como se cada um se visse no outro e, portanto, o sucesso do outro representa o próprio sucesso.

${ }^{11} \mathrm{~J}$ havia escrito: "KET - Pobre Valente (pensei) serto com medo e asustado" [o cachorro havia desaparecido e por isso a personagem Kat pensava que ele deveria estar assustado.]. 
Com relação à troca de conhecimentos, foi possível observar que os sujeitos trouxeram para a terapia em grupo saberes construídos em sessões anteriores. A própria J ao dizer pensa em resposta a minha observação aqui não épensei... trouxe o conhecimento de que os verbos das indicações das açôes cênicas deveriam estar no tempo presente na peça de teatro. $\mathrm{D}$, do mesmo modo, ao dizer que teria de colocar a personagem falando ou fazendo alguma coisa para demonstrar seu pensamento em cena, mostrou que já havia se apropriado de um dos aspectos da produção escrita desse gênero. $M$, por seu turno, ao perguntar se o pensamento da personagem era importante $(\dot{E}$ importante? Se é importante não dá pra tirar) também apresentou uma informação interessante para a interação, uma vez que a adaptação do romance para a peça pressupõe a manutenção de aspectos relevantes da trama original, com vistas à (re)criação de sentidos. $\mathrm{D}$, ao ouvir a leitura de $\mathrm{J}$ a respeito do pensamento da personagem, disse imediatamente que não daria uma ação, demonstrando a aprendizagem de uma das propriedades do gênero em estudo.

Se pensarmos em termos de atividade mental, ou melhor, em desenvolvimento cognitivo provocado pelas açóes epilinguísticas socializadas, podemos recorrer a Bakhtin (2006). O autor diz que "a base da atividade mental em língua materna" é considerada como forma de desenvolvimento do pensamento e da consciência. Em outras palavras, a linguagem é que possibilita o desenvolvimento cognitivo; "não existe atividade mental sem expressão semiótica [...] o centro organizador e formador não se situa no interior, mas no exterior" (BAKHTIN, 2006, p. 116). Bakhtin afirma ainda que é a linguagem que organiza o pensamento, dá-lhe forma, modela-o e determina sua orientação. Assim, ao pensarmos que o conhecimento é constituído na intersubjetividade das relações sociais, somos levados a crer que a aprendizagem $\mathrm{da} /$ sobre a linguagem dos sujeitos desta pesquisa, como mostrado acima, foi produto de um saber construído na interação.

Antes de os sujeitos demonstrarem (conhecimentos pontuais) de forma autônoma, eles necessitaram experimentar esses mesmos conhecimentos socializados (por meio da linguagem) intersubjetivamente, ou seja, o conhecimento socialmente adquirido começa a ser parte do conhecimento individual do sujeito à medida que ele começa a utilizá-lo de forma independente. Os sujeitos que no início dos atendimentos rejeitavam as atividades de leitura e escrita, agora, na medida em que participam de práticas sociais de linguagem, não só aceitam como se engajam nesta atividade e se comprometem com a aprendizagem grupal e desenvolvimento individual. Percebemos um estado (gradativo) de transformação e de constituição de leitores e escritores/autores. 
Nesse dia também eu havia sugerido a J que ajudasse um colega que estava com dificuldades:

(03) [19/03/09]: Referente ao capítulo 13 do romance, reenunciado por ED.

(ED fica em dúvida sobre uma indicação e fica esperando, enquanto a T está falando com o M).

[...]

T: Precisa de ajuda? (diz para ED) Pede pra J.

J: (vai sentar ao lado dele). Que é, pode falar...

ED: Aqui... Tá certo? (lê um trecho do seu texto) "Eu espiei Daniel estava sentado são e salvo..."

J: Espia... tu escreve "espia”... [referindo-se ao tempo verbal da indicação cênica]

T: Isso, só não vai o 'eu', lembra? [...] É o que a J falou... Se você coloca espia nem dá pra colocar o eu... Existe 'eu espia'? Kat espia Daniel sentado. Existe 'eu espia'?

J: Não!

T: Por que que não precisa colocar o eu?

ED: Hum?

T: Porque na indicação do personagem... quando você coloca o nome do personagem e daí o que ele tem que fazer... como ele tem que falar... Que nem aqui [mostra uma passagem já escrita por ED]. Você colocou 'Daniel, eu sussurrei, é você?' Que eu é esse? Quem que tá sussurrando isso?

ED: A Kat.

T: [...] Quando você diz Daniel, eu sussurrei, é você? É como se a Kat tivesse contando isso... Ela só conta no livro... O roteiro indica as falas... indica as ações...

$[\ldots]$

T: Então, coloca Kat, daí sussurra [escreve: Kat (sussurra) - Daniel, é você?] [...] Não precisa por o 'eu'... quem tá sussurrando já tá aqui...(aponta para Kat).

Na primeira parte do episódio é possível observar o quanto J se dispõe a ajudar, a ponto de sair de seu lugar e ir sentar-se ao lado de ED. J consegue responder parte da dúvida de ED e se mostra satisfeita com isso. Tal satisfação decorre provavelmente do fato de ela se sentir valorizada e incluída no grupo, de constituir-se como sujeito que aprende, mas que também ensina, ou seja, tem o que dizer ao outro. A função da terapia vai além da constituição de um ambiente significativo para a apropriação da linguagem escrita; sua função inclui a criação de um ambiente onde o sujeito se sinta incluso, necessário ao grupo, ou, em outras palavras, é favorecer um sentimento de pertencimento (MACHADO, 2007). Assim, a situação de exclusão vivenciada em muitas escolas e refletida nos discursos das famílias, dos professores e das próprias crianças, deve ser revertida em uma situação de inclusão. A recuperação da 
autoestima é fundamental para o progresso em terapia. E o terapeuta à medida que valoriza seu sujeito/paciente, que delega a ele funções dentro do grupo, que significa e interpreta suas ações de linguagem, está colaborando para a recuperação da autoimagem abalada no contexto escolar e familiar.

Compreender a história de J, incluídas aí as interações vividas no contexto da escola, sua relação com a escrita e, da mesma forma, compreender seu percurso de apropriação em torno do objeto, suas hipóteses e seu lugar no grupo de terapia, ou seja, compreender J como um ser humano histórico e social é devolver a ela a sua condição de sujeito que aprende, ensina e, com isso, se desenvolve. Além do mais, ao pensarmos na questão da subjetividade e no processo de aprendizagem da linguagem escrita e relacionarmos essas questôes com a história de J e dos outros sujeitos do grupo terapêutico, recorremos a Soares (2008, p. 81), que nos ajuda a compreender de que forma esses sujeitos podem ser vítimas do processo de escolarização. Para a autora, muitas escolas ensinam ao aluno que a "produção de textos" representa um momento de demonstração de habilidades previamente adquiridas, como, por exemplo, grafar as palavras dentro do padrão da norma ortográfica. $\mathrm{O}$ resultado é que

o processo de aquisição da língua escrita, na escola, é, desde o primeiro momento, um processo de desaprendizagem da escrita com as funções de interação autor/leitor, de intersubjetividade, e de aprendizagem de uma escrita que, em vez de interação, é reprodução de um modelo escolar de texto, é "prestação de contas" do autor a um leitor que nada mais espera senão reconhecer, no texto produzido, esse modelo; que, em vez de possibilidade de intersubjetividade, é, ao contrário, negação da subjetividade de autor e leitor, porque um e outro se negam como sujeitos, na escrita/leitura do texto.

Assim, nesse modelo de escola perde-se a subjetividade intrínseca à construção do conhecimento sobre o funcionamento da língua escrita. Sem o tu não existe o $e$ u e sem o $e$ não existe o ele. Em outras palavras, sem o outro que constitui o $e u$ perde-se a relação interativa e sem esta não se aprende uma língua (o ele); no máximo, "aprende-se" um código ${ }^{12}$ de transmissão de mensagens. Nas relações interativas com o grupo terapêutico foi possível redimensionar essa relação negativa dos sujeitos com a escrita.

12 "O código é apenas um meio técnico de informação, não tem significado criador cognitivo. O código é um contexto deliberadamente estabelecido, amortecido." (BAKHTIN, 2003, p. 383). 
No excerto acima, ao observar que ED precisava de auxílio, sugeri a ele que recorresse a J para ajudá-lo com o intuito também de fazer com que J percebesse suas capacidades e conhecimentos sobre a linguagem e, de modo particular, sobre os construtos acerca da escrita de uma peça de teatro. Nessa situação, J diz a ED que ele deveria colocar na indicação da cena o verbo espiar no tempo presente. Também quando eu disse a ED: É o que a J falou. Se você coloca espia nem dá pra colocar o eu, tive por finalidade reiterar a contribuição dada por ela na situação em questão, já que a troca de conhecimentos no grupo é um dos motivos para a sua existência. Também quando, na sequência, eu disse existe eu espia? intentei fazer com que ED fizesse uso do conhecimento linguístico que já possuía trazendo-o para a situação de produção de linguagem.

O trecho escrito por ED, resultante do diálogo analisado, segue abaixo:

KAT - Danieu (fala aos gritos) Onde você está? (derepente escuta um barulho baixo e estranho de trás da garagem) - Danieu (susurra), é você?

(Daniel estava sentado são e salvo)

Por que você se escondeu?

DANIEL - Eu estava com medo (murmura) pensei que o grool ia explodir ou alguma coisa desse tipo.

[19/03/09]: Trecho escrito por ED.

Continuando o processo de análise da produção da peça de teatro em grupo, mostro, a seguir, um episódio em que L sugere ao colega como adequar um possível problema ocorrido durante a produção do texto:

(04) $[19 / 03 / 09]$

(M escreve um bom trecho sozinho e observo que ele está esquecendo de indicar os personagens).

T: $M$ você tá esquecendo de uma coisa...Fala pra ele $\mathrm{L}$, o que ele tá esquecendo...

L: (Olha o texto) Do nome das pessoas...

M: Tô esquecendo o quê?

T: Quem é que tá falando aí?

M: Agora deixa.

T: Não dá pra deixar.

M: Não vou fazer tudo de novo não.

L: Coloca aqui fora. Não precisa fazer de novo...

Em um primeiro momento tive de pedir a L que observasse o que estava inadequado no texto de $\mathrm{M}$. Considerei que era necessário sugerir ajuda ao grupo, visto que mesmo que cada integrante estivesse centrado na produção de sua parte da peça, pois cada um deles estava reenunciando um capítulo diferente do livro, havia o objetivo do trabalho da terapia em grupo e o 
objetivo imediato dos sujeitos, que era o de produzir uma única peça para a publicação em coautoria. Meu intento, então, tentando criar situações de interação dentro do grupo, já que todos tinham metas em comum, foi de ir instigando as trocas de conhecimentos entre eles, objetivando fazer com que eles recorressem também uns aos outros em caso de dúvidas, e não apenas a mim, uma vez que parto do pressuposto de que a aprendizagem ocorre na mediação com o outro, o que inclui o parceiro de terapia. Nesse dia percebi que L, mesmo não tendo a atitude inicial de ajudar o colega, já que estava concentrado na elaboração do seu texto, depois de apontar o problema na parte do roteiro de $M$, não voltou para o seu trabalho e, sim, espontaneamente permaneceu atento à discussão travada, sugerindo a $\mathrm{M}$ uma solução possível para a colocação das indicações dos personagens. A propósito, $\mathrm{M}$ realizou o sugerido pelo colega e colocou a indicação na margem da folha de papel.

A seguir, é possível continuar observando o processo de mediaçãoensino-aprendizagem no processo de interação do grupo na clínica:

(05) [19/03/09]

M: T, essa parte quando ela fala de como é o carro da tia, o vestido da tia, essa parte não coloca, ou coloca?

T: (para todos) Que que vocês acham?

(silêncio)

T: Como é que ficam as descrições na peça? É só pensar um pouco... Livro e peça... O livro eu leio a peça eu...

ED: Vê... a gente vê, que nem novela...

T: Então, na novela a gente tá vendo a roupa das pessoas, a gente tá vendo tudo, certo? E no livro a gente vê o quê?

ED: Vê nada.

J: Só letrinha...

T: Então, qual é o recurso do livro? Que que o autor tem pra mostrar como é o carro da tia, como é o vestido da tia? Como é que é a tia? [Tia Loise, tia de Kat e Daniel]

M: $\mathrm{O}$ autor tem que escrever tudo...

T: Isso, tem que descrever tudo e a gente imagina tudo na nossa cabeça... Na peça, a gente vê, na novela, no filme... Algumas descrições a gente vai ter que fazer depois lá no topo das cenas [macrorrubricas]... quando a gente for dividir [a peça] em cenas... ${ }^{13}$

M: As roupas também? [referindo-se à descrição do figurino]

13 Lembremos que a divisão da peça em cenas, com marcação das vistas/ macrorrubricas, ocorreu em um segundo momento de escrita. 
Destaco, pela análise do episódio acima, outra construção de conhecimentos em grupo, referente à seguinte questão: Como, em um processo de adaptação, reenunciar as sequências descritivas do romance para uma peça de teatro? Foi preciso trazer a situação social de interação autor/público e, com isso, a própria materialidade dos dois gêneros em foco (romance e peça de teatro), para podermos abordar a questão acima exposta. Desse modo, ao dizer o livro eu leio, a peça eu... eu estava intentando fazer com que os sujeitos refletissem sobre a situação de interação dos dois gêneros. $\mathrm{ED}$, ao responder a gente vê que nem novela, demonstrou conhecer que as particularidades dos dois gêneros repercutiam na composição textual. Durante a discussão foram surgindo outras dúvidas, como a de M: $e$ as roupas?, que iam guiando a interação no grupo e proporcionando a formação conjunta de saberes sobre a textualização dos processos descritivos no romance e na peça de teatro.

Ao tratar da sequência descritiva, podemos retomar novamente a artificialidade das situações de "ensino" de produção de textos na escola e compreendermos mais um pouco a recusa dos alunos a estas "práticas de linguagem". Ao pensarmos em categorias abstratas como descrição, narração, dissertação etc, e na tortura de alunos exercitando tais categorias, podemos igualmente compreender porque, apesar de anos de ensino formal, muitos sujeitos rejeitam as atividades de leitura e escrita e demonstram dificuldades em posicionarem-se como leitores e escritores frente a tais práticas. Não conseguem não por problemas biológicos, individuais, orgânicos, mas pelo fato de que não estiveram expostos a eventos concretos de uso da linguagem.

Nas situaçôes de mediação-ensino-aprendizagem, a noção de gêneros representa, portanto, um avanço, não somente na escola, mas em contexto de clínica é possível que trabalhemos em uma perspectiva enunciativa, com a linguagem em situação real de uso. É dessa maneira que a aprendizagem se efetiva. Assim, vale ressaltar que não trabalhamos com esse conceito - descrição - enquanto categoria abstrata, mas, sim, como um recurso constitutivo às configuraçôes textuais de gêneros como o romance, ou seja, em situaçôes em que essas categorias (narraçōes, descriçōes) são necessárias para o funcionamento do discurso. Nesta pesquisa, ao trazermos os gêneros romance, peça de teatro e sinopse, abordamos as sequências narrativa ${ }^{14}$ e descritiva, que, trabalhadas

\footnotetext{
${ }^{14} \mathrm{O}$ aspecto narrativo, por exemplo, fez com que os sujeitos refletissem sobre o funcionamento da especificidade da narração enquanto aspecto do discurso, como também operassem (na reenunciação) a transformação das partes narrativas presentes no romance em outros recursos possíveis na peça, como diálogos e indicações de cenas.
} 
no nível do discurso, como procedimentos de textualização, passaram a receber o status de categorias concretas.

A respeito do avanço que a noção de gêneros pode trazer para a escola e, no nosso caso, para a clínica, no que diz respeito à proficiência em relação à leitura e produção textual, dizem Pompílio et al. (2008, p. 103):

se tomarmos como princípio que a língua se dá nos gêneros, nas interações discursivas que ocorrem entre os interlocutores nas situações de produção de linguagem, podemos propor novos modos de ensinoaprendizagem de língua, em que os alunos possam ser colocados "em situação de produção de linguagem" (ou seja, em uma situação mimética em relação à situação original de produção do gênero, qualquer que seja ele) e, com isso, trabalhar simultaneamente escrita, leitura e reflexôes metalingüísticas, conduzidas pelo gênero em questão.

Fecho minhas consideraçōes acerca do episódio em análise com a citação acima, na qual as autoras falam do avanço que a noção de gêneros pode trazer para as situações de ensino e aprendizagem na escola. Como já mencionado, trago tais contribuições para o contexto de clínica. Contudo, a questão para nós fonoaudiólogos ultrapassa fatores relacionados a aspectos de apropriação da linguagem escrita propriamente ditos. Em situação de clínica, repito, temos de trabalhar para dar um novo sentido à relação do sujeito com a linguagem, por isso a noção de gêneros pode significar mais do que ensinar, aprender, mediar, pois possibilita ao profissional resgatar esses sujeitos, ou seja, construir com eles uma relação produtiva com a escrita.

Abaixo, o texto (reenunciação do capítulo 15 do livro) de $\mathrm{M}$, produzido durante a sessão que resultou no episódio dialógico acima:

[19/03/2009] Produção textual de M

[MÃE $]^{15}$ - Crianças, Tia Loise vem amanha, e amanhã quando voltarem da escola arrumen seus quartos.

[KAT] - (diz feliz) Tia Loise é minha tia preferida. Mesmo sendo um adulto ela é muito brincalhona.

(é noite: KAT está no quarto)

[KAT] - minha tia vem amanha e ela vai me ajudar a me livrar de você para senpre (sussurra para o grool)

${ }^{15}$ As indicações de personagens entre colchetes estão assim representadas porque foram colocadas (na margem da folha) por $M$ após a discussão sobre seu "esquecimento". 
(No dia seguinte chega tia Loise)

[Tia Loise] - Ei como vão vocês?

KAT - (corre a abraça a tia). Tia suba comigo agora, é super inportante (estão indo para o quarto) você já ouvio falar em grool? E de lanx?

Tia Loise - Nunca ouvi falar

KAT - (Mostra o grool para sua tia) Olhe!

Tia Loise - Então você é um grool (se abaixa para pegar o grool)

KAT - Espere (grita) tauves seja melhor não tocar nele.

Depois da sessão aqui apresentada, os sujeitos seguiram em processo terapêutico. Após a produção da peça, esta passou por sessões de revisão de texto, que ocorreu com a finalidade de publicação. Depois de escrita, revisada e produzida a sinopse, a peça foi publicada no site do Recanto das Letras e encenada pelos sujeitos.

Vale ressaltar que o trabalho com o gênero peça de teatro em uma perspectiva enunciativo-discursiva teve por objetivo criar uma situação dialógica geradora de processos reflexivos em torno da linguagem. Assim, por exemplo, na produção escrita de textos no gênero por cada sujeito, fui a interlocutora imediata a fim de, por meio de algumas perguntas/consideraçóes, propiciar ao outro, sujeito da terapia, uma postura analítica e crítica necessária à construção de conhecimentos linguístico-discursivos. Acredito, como postula Bakhtin, que as palavras do outro se materializam nas nossas próprias palavras, como no caso da apropriação de um dado gênero, quando a esse outro são dadas as condições para que a aprendizagem se efetive; condições essas que passam pela elaboração de um projeto de discurso que envolva, entre outros aspectos, uma finalidade enunciativa e um interlocutor definido. Nesse sentido foi possível observar que os sujeitos do grupo foram hábeis na produção da peça de teatro, uma vez que produziram textos adequados ao gênero abordado em terapia, ao mesmo tempo em que desenvolveram competências linguísticas e discursivas necessárias ao enfrentamento das demandas sociais de leitura e escrita.

\section{Considerações finais}

Acredito que atender crianças e adolescentes encaminhados por suas escolas com queixas de dificuldades de leitura e escrita demanda, entre outras coisas, que se compreenda a relação de rejeição que esses sujeitos constroem em relação à escrita. Essa rejeição não representa, em muitos casos, uma rejeição à linguagem, mas, sim, à proposta de trabalho com a linguagem desenvolvida pelas escolas das quais os sujeitos provêm. 
Posso afirmar, com base nos resultados desta pesquisa, que os sujeitos passaram a se envolver e se engajar nas práticas de linguagem desenvolvidas na clínica, apresentando avanços em suas condições de leitores e produtores de textos. Nesse sentido, posso reafirmar que as práticas fonoaudiológicas embasadas na teoria de Bakhtin, ao possibilitarem a aproximação do sujeito com a linguagem e, com isso, viabilizarem a aprendizagem, contribuem para a ressignificação da queixa.

Vale mencionar os discursos apresentados pelos sujeitos da pesquisa: J parecia incomodada em sala, pedia para sair da sala de aula, dizia ter dores de cabeça e de barriga. M dizia que sentava no fundo da sala e simplesmente não fazia as atividades propostas pelos professores. ED dizia que detestava ler e escrever e, segundo relatório escolar, tinha dificuldades de se manter sentado na cadeira. O relatório da escola de L dizia que ele estava sempre distraído, com o olhar distante e que nunca entendia as explicações dadas pelos professores. $\mathrm{D}$, por seu turno, dizia que escrevia tudo errado devido à constante troca de grafemas e que não gostava de ler e escrever. É possível na análise desses discursos observar quão distantes estavam dos usos da linguagem escrita na esfera escolar. Pretendi, durante a prática clínica, (re)aproximá-los, engajá-los, comprometêlos com as situações de produção de linguagem. Resultado esse que foi alcançado, pois eles se engajaram, comprometeram-se com o trabalho em desenvolvimento e, com outra imagem acerca da linguagem escrita e de si próprios, produziram discursos, tornaram-se leitores e escritores mais eficientes/proficientes. Considerando que todos nós interagimos por meio de gêneros do discurso, vimos a necessidade de focar nos gêneros o jogo dialógico que se efetiva na construção da significação. Trabalhando na teoria de gêneros, portanto, estamos trabalhando na concretude do fenômeno da linguagem.

Diferentemente de perspectivas que desconsideram o caráter constitutivo da linguagem e o enunciado como fenômeno concreto da interação discursiva, ao proporem, por exemplo, atividades centradas na estimulação de sons instrumentais e sons verbais isolados (completamente abstraídos dos aspectos funcionais da língua) vimos, por meio deste estudo, uma perspectiva teórica de ação fonoaudiológica operar na (re)constituição da subjetividade. 


\section{Referências}

ABAURRE, M. B. M. Uma história individual. In: ABAURRE, M. B. M.; FIAD, R. S. F; MAYRINK-SABINSON, M. L. Cenas de aquisição da escrita: o sujeito e o trabalho com o texto. Campinas: Mercado de Letras, 2006

BAKHTIN, M. Marxismo e filosofia da linguagem. São Paulo: HUCITEC, 2006.

BAKHTIN, M. Estética da criação verbal. São Paulo: Martins Fontes, 2003.

BERBERIAN, A. P.; MASSI, G. A. A clínica fonoaudiológica voltada para os chamados distúrbios de leitura e escrita: uma abordagem constitutiva de linguagem. Revista da Sociedade Brasileira de Fonoaudiologia, v. 1, n. 10, 2005, p. 43-52.

COUDRY, M. I. H. Diário de Narciso: discurso e afasia. São Paulo: Martins Fontes, 1988.

GERALDI, W. Portos de passagem. São Paulo: Martins Fontes, 1997.

MACHADO, M. L. Grupo de linguagem escrita: uma proposta de intervenção fonoaudiológica. 2007. Dissertação de mestrado. Universidade Tuiuti do Paraná. Curitiba: UTP, 2007.

MARGALL, S. A função auditiva na terapia dos distúrbios de leitura e escrita. In: SANTOS, M. T. e NAVAS, A. L. Distúrbios de leitura e escrita. São Paulo: Manole, 2004, p.263-328.

MASSI, G. A dislexia em questão. São Paulo: Plexus, 2007.

POMPÍLIO, B. W. et al. Os PCNs: uma experiência de formação de professores do ensino fundamental. In: ROJO, R. (Org). A prática de linguagem em sala de aula: praticando os PCNs. São Paulo: Mercado de Letras, 2008. p. 93-126.

SOARES, M. Alfabetização e letramento. São Paulo: Contexto, 2008. 